\section{A NOVEL TYPE OF HAY STACKER}

BY DR. ALFRED GRADENWITZ.

A novel type of hay stacker has recently made its appearance in Germany. The stacker renders it possible to unload and stow away a cartload of hay in eight minutes and with the aid of only three men.

In constructing the stacker, special regard was paid to portability.

$\mathrm{T} \mathrm{h}$ e device consists of a light, yet substantial iron construction having a rotary support fitted with a hoist and a boom for picking up the load. A grip or a straw tongs is used. $\mathrm{T} \mathrm{h}$ e rotary support consists of two U-iron frames fitted with a pivot, at top a $\mathrm{n}$ d bottom, and telescoping one into the other. The total length of the rotary support, that is the distance apart of the pivots, is altered at will, the adjustment being effected by means of bolts. The free end of the boom is suspended from a chain running over two rollers, one being fitted in the upper and the other in the lower frame; the chain is fixed by its upper end. In case the position of the boom is such that the stress of the chain due to insufficient to avoid a deflection of the rotary support, the chain is fixed at the upper roller by means of a pin, and its tension regulated by a special device.

The rope running over the roller fixed to the end of the boom is wound up by means of a winch, with the usual dog and gear, to enable even heavy loads to be readily lifted by a single man. In order to lower the load rapidly, the driving wheel of the winch is thrown out of gear axially, the speed being controlled by a hand brake.

The two pivots of the crane turn in bearings fixed to the timber above and below. As soon as a space corresponding with the double loading range of the crane has been filled with hay, the crane is shifted to the next loading eenter, arranged at the double distance of the projection of the crane, and so on, a pair of pivot bearings being arranged for each loading center.

The discharging is effected as follows: A man standing on the hay or corn throws the open tongs or fork, which holds a quarter or a third of a cartload, to presented by the seedless orange, and is in fact a pro. totype of the latter. When the seedless orange was introduced to the public, it was regarded in the light by what uncanny method was their kind propagated. Shrouded in a mystery such as this, it required some little time for the matter-of-fact virtues to impress the real merits of the fruit to b e c o m known; b u known, b ut once eaten, its subtle qualities were forgotten, and its advan tages $w$ e $r$ e quickly appreciated, a n o ciated, a $\mathrm{n}$ d from that day to this the old fashioned vari. ety, with its multiplicity of seeds, has suffered severely, having been almost driven

A SEEDLESS, CORELESS, BLOOMLESS APPLE.

a great depth into the load. The man handling the crane winds up the rope and swings the crane over the place where the charge is to be stowed. The man on the stack at the same time, by drawing the disengaging tow, causes the catch to be opened, which was closed by its own weight and the weight of its load. The load as it drops out is distributed. After the crane has swung back, the operation is renewed.

\section{A SEEDLESS, CORELESS, BLOOMLESS APPLE.}

Everyone is familiar with the seedless or nave orange, but the seedless apple is a new fruit on the market.

This marvelous improvement in the common apple, fulfilling in letter as well as in spirit the jest of the schoolboy, who proclaimed that "there ain't going to be no core," would seem to indicate that the new apple will eventually monopolize the markets of the world, for reasons which the appended data clearly point out.

By way of illustration, it may be said that the seed. less and coreless apple follows closely the analogue all but ouc of the race. Now let us ascertain the real difference between the two varieties of the oranges, as the comparison will serve a useful purpose when the old and the new species of apples are being similarly considered. The reason seedless oranges are universally preferred to those that contain ovules is not because any saving is effected, but simply that the seeds are in the way. The ordinary apple presents a wholly different aspect, for the seeds are inclosed in hard pockets that represent at least one-fourth of the apple, and which cannot be utilized in any way as an article of food, whereas in the seedless variety these disagreeable features are entirely eliminated. Still, what is more to the point of economy, apples without seeds are also wormless, for it is well known to growers that worms in apples obtain their sustenance not from the meat, but from the seeds; hence it is evident that if a worm was hatched in a seedless apple, it could not live.

The beginning of the seedless apple dates back only a few years, and therefore its history is necessarily (Continued on page 102.)

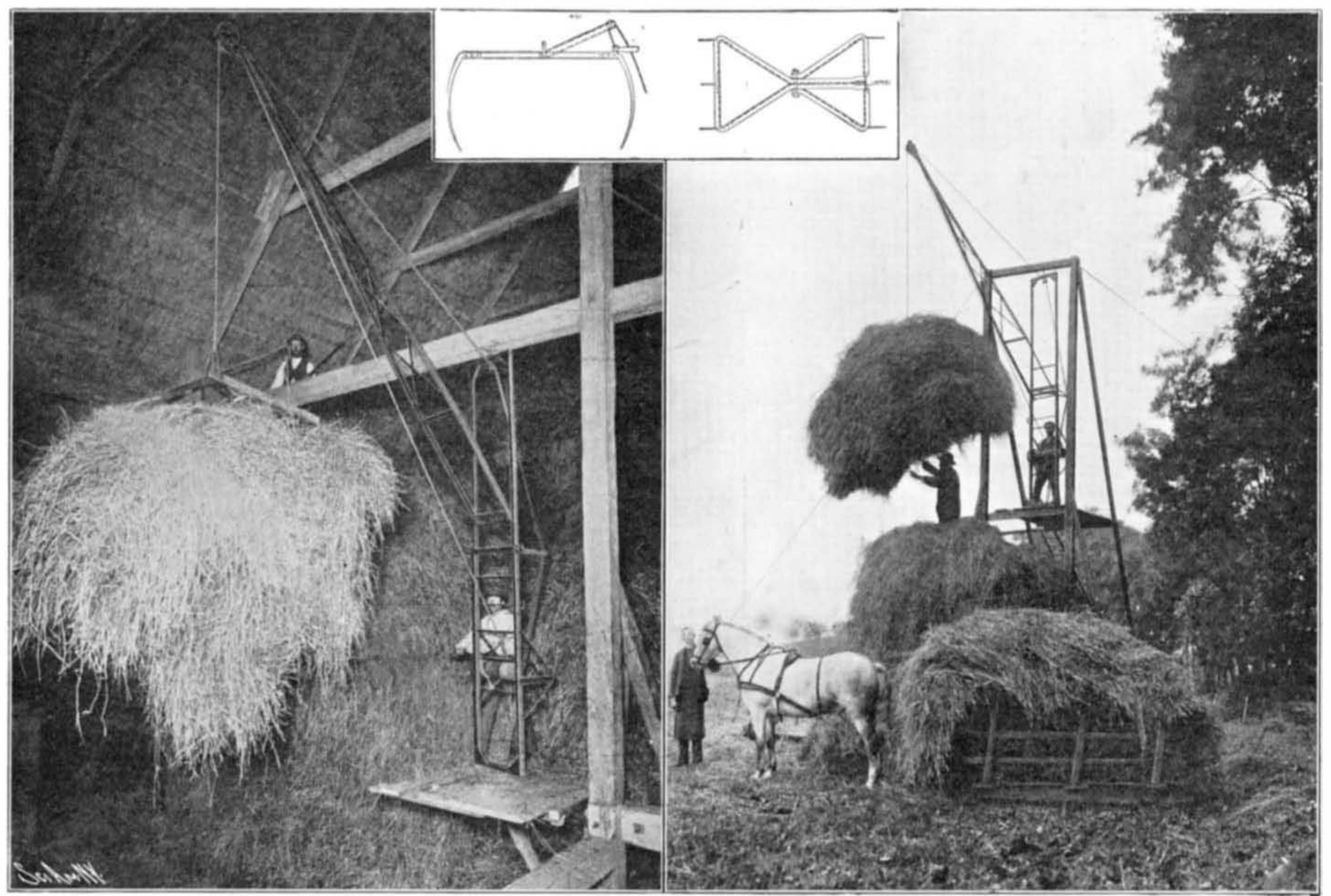

The Hay Stacker Set Up in a Barn. 
provided a large crypt, which will be utilized for the tombs of naval officers, whom it is desire to inter at this historic place. In fact, this feature of the chapel may be compared with that provided at Westminster Abbey in London. The crypt floor will be 12 feet below the main floor, and will be entered both from the interior and the exterior.

\section{A SEEDLESS AND CORELESS APPLE.}

(Continued from page 100.)

brief. All the credit for the propagation of the apple thus far belongs to Mr. John F. Spencer, of Grand Junction, Col., who, struck with the success of the seedless orange, believed that similar results could be ob-
taine with apples.

After several years' experimental research he sucless, and wormless apples, and from this little group there has budded two thousand more trees, which at present constitute the entire seedless apple stock of present constitute the entire seedless apple stock of
the world; and from these two thousand trees all. the rest of the world must be supplied. It is estimated that these will have produced about three hundred and seventy-five thousand nursery trees by the fall of 1905, and that the following year at least two million five hundred thousand trees will furnish the supply. five hundre thousand trees will furnish the supply.
There are many striking peculiarities in the developThere are many striking peculiarities in the develop-
ment of the seedless tree, as well as in the fruit. As an instance, it may be cited that the tree is blossomless; and while there is a stamen and a very sma quantity of pollen, exactly as in the blossom of the ordinary apple tree, yet the blossom or flower itself is missing. The photograph shows the only bloom, flowmissing. The phelograph shows the only bloom, flow-
er. or blossom that ever appears on the seedless apple

The only thing that resembles a blossom comes in the form of several small green leaves that grow aroun the little apple to shelter it. It is this lack of blossom that makes it almost impossible for the codling moth to deposit its eggs, and this practically insures a wormless apple. As it is the blossom of the common apple tree that is attacked by cold and frost, the seedless apple tree is immune, and the late frosts that play havoc with the apple grower's purse by denuding his orchard may now become a thing of the past, and the same time prevent worry and increase profits.

The seedless apple tree has a hard, smooth bark, and may be grown in any climate; the meat of the new apple, like that of the seedless orange, is very solid, and in both there is a slightly hardened substance at the navel end. Through long development this has almost disappeare in the orange; and while it is more or less prominent in the seedless apple, it has been materially reduced on the last generation of trees, and all sizes tend to show that it will grow smaller with successive generations, as the navel end of the orange has grown smaller.

The apples, which are of a beautiful dark-red color with yellow strawberry dots, are of a goodly size and have a flavor similar to the Wine Sap.

\section{The current supplement.}

"The Coal and Ore Handling Plant in the Island of Elba" is the title of an article that opens the current SuPPLEMENT, No. 1518. Illustrations, both photographic and diagrammatic, accompany the text. A brief but instructive account of the Wachusett reservoir and dam instructive account of the Wachusett reservoir and dam eral methods of preparing aquatic leathers. Peter Eyermann, one of the staff who had charge of Machin ery Hall and allied exhibits at the World's Fair, has designed a locomotive and a steamship which are to be driven by producer-gas. These designs are published in the current SupPLEMENT with a full description. A. Frederick Collins writes on the De Forest-Ives electric
wave-length standard. Ancient and modern methods of measuring time was the subject of the Christmas lectures at the Royal Institution. An abstract of these lectures is published. Edmund Otis Hovey writes on the Seventeenth Annual Meeting of the Geological Society of America. The Bureau of Census has just published a bulletin showing the conditions of irrigation in the United States in 1902. This bulletin is reviewed. An elaborate article on the Transmission of Yellow Fever by Mosquitoes is ublished. We print the last installment describing the Paris Automobile Show.

A new form of incandescent lamp in which vapor ize petroleum spirit is used has been devised. The principle of the invention is a petroleum spirit vessel place at a higher level than the burner. From this vessel the gasoline gravitates through a tube to a tile liquid into a generator, where it is vaporize through being heated by a separate flame. The gas then passes through a needle valve, receives its correct proportion of air, and is then ignited in a burner fitted with an ordinary incandescent mantle. An intense light is produced. To start the lamp, the vaporizer has to be heated, and this is acomplished by the ignition of a little methylated spirit poured over asbestos contained in a tray placed below the needle valve. The petroleum consumption of the lamp, with the maximum light is very economical, one quart of spirit be ing sufficient to give a light of 150 candle power for sixteen hours. Though the inherent dangers atiending the use of petroleum are by no means obviated in this the use of petroleum are by no means obviated in this
device, it constitutes sn excellent lamp for out oor use.

\section{New Radium Theories.}

Two announcements, one by Prof. Monroe Snyder the other by Prof. E. Rutherford, of McGill University, Montreal, Canada, have recently been made, which are of so startling a nature that, had they come from less trustworthy sources, they would have been immediately discredited.

Prof. Snyder, in a preliminary paper read before the American Philosophical Society, discoursed on his discovery of radium in the photosphere of the sun. Prof. Snyder finds in radium the cause of the hea and luminosity of the celestial bodies. In his opinion, variable stars are caused, not by the revolution of one body about another, but by the regular fluctuation of light, which is due to periodical outbursts of radioactivity. "The professor concludes that the sun is a variable star with a period of eleven years, and that the sun spots are one of the demonstrations or results of these outbursts of radium emanations. The problematical rings of light so characteristic of many of the nebulæ are accounted for by Prof. Snyder by treat ing them as transition stages of radioactivity.

Prof. Rutherford holds that the radioactive substances are the cause of the earth's heat. His theory is promulgate in a recent number of Harper's Magazine. In that periodical, after reviewing Kelvin's mathematical deduction of the earth's age, he formulates his theory. The following are abstracts from his article:

"While the heat supplied by possible chemical combination is quite inadequate to account for the heat of the sun and earth, the recent discovery that the radioactive bodies are able to emit an amount of heat about one million times greater than is evolved in the most violent chemical reaction, throws quite another light on the question. In the course of a year, one pound of radium would emit as much heat as that obtained from the combustion of one hundred pounds of the best coal, but at the end of that time the radium would apparently be unchanged and would itself give out heat at the old rate. It can be calculated with some confidence that, although the actual amount of heat per year to be derived from the radium must slowly decrease with the time, on an average it would emit heat at the above rate for about one thousand years.

"But a still more remarkable fact remains to be noticed. Dr. Barnes and the writer showed that more than three-quarters of the heating effect of radium was due to the radioactive emanation store in it.

"Sir William Ramsay and Mr. Soddy have recently found that the volume of the radium emanation stored in one gramme of radium is about one cubic millimeter at atmospheric pressure and temperature. The emanation is known to be a heavy gas, and, taking its molecular weight to be one hundred times that of hydrogen, it can be readily calculated that if one pound weight of the emanation could be collected, it would initially, radiate energy at the rate of about 8,000 horse-power. This output of energy in the form of heat would fall off with the time, but the total amount of energy liberate during its life corresponds to that require to drive an engine of 10,000 horse-power for five days.

"Since there is little loubt that a quantity of radium, left to itself, would in the course of time completely change into the emanation and other products, we see that at least an equal quantity of energy must be given out by radium during its transformation. According to present views, the emission of heat is a consequence of a breaking up of the radium atom into a succession of radioactive products. The disintegration is explosive in character, and is accompanied by the projection of a flight of material particles with great velocity.

"Since all the radioactive bodies emit particles, each of them probably emits heat at a rate proportional to probably only about one-millionth part of that shown by an equal weight of radium.

Although the radioactive substances are found in the greatest quantity in pitchblende, radioactive matter has been found to be distribute to a minute extent throughout the atmosphere and the earth's crust. Much of our information in this important field has been due to the splendid work of Profs. Elster and Geitel, teachers in the High School of Wolfenbüttel, Germany.

"The emanations of radium and of other radioactive substances are present everywhere in the atmosphere. Every falling rain-drop and snowflake carries some of this radioactive matter to the earth, while every leaf

and blade of grass is
radioactive material.

"These emanations are not produced in the air itself, but are exhale from the earth's crust, which is impregnated with radioactive matter. The air in confined spaces like caves and cells is, in most cases, very radioactive on account of the presence of emanations which have diffused from the soil. The radium emanation has been found in the water from deep wells and springs, in surface and lake water, in escaping natural carbonic acid, and in the oil from wells. Elster and Geitel have shown that the soil itself is radioactive to varying degrees, the activity being most marked in clayey deposits.

"Since the radioactive substances present on the earth are continuously expelling $\alpha$ particles, heat must be evolved in amount proportional to the quantity of active matter present and to the intensity of its radiations. The question then arises, is the amount of radioactive matter present in the earth sufficient to heat it to an appreciable extent? I think that, even with our present knowledge, this question must be answere in the affirmative.

"Taking the value of the conductivity of rock used by Lord Kelvin, and knowing the average temperature gradient, the amount of internal heat lost per second from the earth by conduction to its surface can readily be calculated. Since one gramme of radium emits enough heat each hour to raise one hundred grammes of water through 1 deg. C., a simple calcusation shows that the present loss of heat from the earth is equivalent to that supplied by the presence of about two hundred and seventy million tons of radium. This amoun may seem very large compare with the small quanti ties of radium hitherto separated, but is small, for example, compare with the annual output of coal from the world. It can readily be deduced that this amount of radium, if distributed uniformly throughout the earth's crust, corresponds to only five parts in one hundred million million per unit mass. This is a very small quantity, and calculations based on the observations of Elster and Geitel show that the radioactivity observed in soils corresponds to the presence of about this proportion of radium. In some soils it is greater, in others less, and in this calculation no account has been taken of the deposits of uranium and thorium materials. A large amount of observations of the materials of the earth for radioactivity will be required before such a conclusion can be considered to be es tablished, but the magnitude of the radioactivity observed is certainly suggestive.

"In this calculation it is not assumed that the radioactivity of the soil is due to radium alone. Other kinds of radioactive matter are undoubtedly present, but, for simplicity, the results are expressed in terms of that amount of radium in the soil require to exhibit the observed radioactivity.

"If radioactive matter is distributed throughout the whole earth to the extent that experiment indicates, the heat evolved by the radioactive matter would compensate for the heat lost by the earth by conduction to the surface. According to this view, the present internal heat of the earth tends to be maintaine by the constant evolution of heat by the radioactive matter contained in it. The calculations of the age of the earth made by Lord Kelvin, which were based on the theory that the earth was a simple cooling body in which there was no further generation of heat, cannot apply, for the present temperature gradient of the earth may have been nearly the same for a long intervăl of time."

\section{Automatic Fire Alarm to be}

Patents have been recently granted to W. L. Denio, of Rochester, N. Y., on a telephone fire alarm system.

This device secures its energy from the central office, so that there is no local battery to get out of order. It consists of one or more signal boxes installed in any building having a telephone. One signal box is sufficient for ordinary purposes, but if one box is place on each floor, a fire starting on that floor would send a signal through that box, which would indicate that particular floor, so that no time would be lost by the fire department in locating the exact seat of the conflagration.

Leading from the signal box is a circuit on which glass-protecte push buttons are locate at convenient points, also thermostats on the ceiling. This signal box consists essentially of an electro-magnet arranged to be energized by the closing of the circuit by a ther mostat or push button, which magnet unlocks a vibrat ing pendulum driven by an escapement wheel and a spring, actuating a revolving star-pointed contact wheel, operating to send in the signal indicating the floor on which the fire occurs. For instance, the wheel 
pointed wheel causes the central exchange light to ficker, and it cannot be mistaken for anything else, because the operator is able to hear the mechanism of the box. The sound is very positive and distinct, and cannot be misunderstoo.

Provision is made for breaking the circuit through the alarm apparatus, after the alarm has been sent in so that there is no interference with the use of the telephone. The thermostats are so constructed that the moment they are subjected to $125 \mathrm{deg}$. of heat they collapse and close the circuit, thus sending in the signal.

It makes no difference whether the telephone lin happens to be busy or the receiver has been carelessly left off the hook, the alarm takes precedence, automatically cutting out everything else until it has gone in and automatically placing the telephone in use again. When the operator at the central exchange receives a signal, she notifies a special operator in charge of the fire calls, who in turn sends the aiarm to fire headquarters, being able from her list of subscriber to tell the exact location of the fire. In the meantime the first operator rings the 'phone bell in the office or building from which the alarm came, thus notifying the person who had sent the alarm that it had been received and the fire department is on the way; or in the event of an alarm's having come from a distant part of the building, a man sitting in his office might be thus warned by the telephone operator that there was a fire in his building, which he had not discovered.

Mr. Denio's patented thermostat and push button circuit is such that it could aimost entirely be destroyed and still the alarm will go in just the same.

\section{THE TURRET AND BARBETTE OF A BATTLESHIP.}

If called upon to name the most important element in a battleship, we would unhesitatingly name the battery, and, more specifically, the 12-inch gun. If this estimate be correct, particular interest attaches to the means of mounting, protecting, and operating the 12 inch gun; and we think that the drawing on the fron page of the present issue will be found to answer very fully any questions that may be asked upon this subject. The illustration is a vertical, sectional view, carried down through the structure of the ship, in the plane of the keel. It includes enough of the ship, in the fore-and-aft direction, to take in the ammunition and handling rooms, and to show the methods of storing the shot, shell, and powder, far down below the waterline, and the means by which it is brought up from its safe

Commencing then at the bottom of the section, we have, first, the outside skin or plating of the ship; then about four feet above that the inside plating, or inner bottom, as it is called. These outer and inner shells extend across the full width of the bottom of the ship and up the sides of it, until they reach a point about 5 feet below the waterline, where the inner shell terminates, the outer shell being continued up to the upper deck, some 20 feet above the waterline. At the point where the inner shell terminates there is formed an offset or ledge, known as the armor shelf, upon which the heavy waterline armor, a foot or so in thickness, finds a footing. The space between the outer and inner bottoms is divided longitudinally by the frames of the ship, which extend across the bottom and up the sides to the main deck; and this double bottom is further subdivided by a series of longitudinal girders, which extend parallel with the keel throughout the length of the ship, and thus serve to divide the space into a large number of separate cells, the whole system thus divided being known as the cellular bottom. Upon the inner bottom, or floor of the hip, in that portion shown in our drawing, and beween that and the first deck above, is a magazine in which is stored the ammunition, or part of it rather, for the rapid-fire guns of 6-inch caliber, which are mounted upon the gun deck and main deck. The ammunition is stacked neatly in racks, arranged as shown in our illustration. At the after end of the magazine is seen the foot of an electrically-operated ammunition hoist, which consists practically of an endless chain belt, provided with racks in which the ammunition is placed and carried to the guns. On the deck above this ammunition room, and arranged centrally below the barbette, is located the handling room, into which open, by water-tight doors, the magazines that contain the powder charges and projectiles for the 12-inch guns. The powder, done up in bags, and the projectiles, are picked up from the rack by an overhead trolley, run out into the handling room, and lowered into the cages of the ammunition hoist. Two decks higher up we come to the steel protective deck, which is from $2 \frac{1}{2}$ to 3 inches in thickness, and extends from side to side, and throughout the whole length of the ship at the level of the waterline. This deck serves to preven the passage of fragments of bursting shell down the magazines, engines, boilers,
Upon the protective deck is erected a great cylindri. cal structure, known as the barbette, whose walls, 8 to 1.2 inches in thickness, consist of solid plates of facehardened Krupp steel. This barbette is practically a circular steel fort; and it is thick enough, and the steel walls are hard enough, to break up and keep out the heaviest projectiles of the enemy, except when they are fired at close ranges. At about two-thirds of the height of the barbette is a heavy, circular track upon which runs a massive turntable. The framing of this turntable extends to a level slightly higher than the top edge of the barbette, and upon it is carried the massive structure of the rotating turret, which is formed, like the barbette, of thick steel armor, bolted to suitable plate steel framing. In plan the turret is elliptical. Its front face, which slopes at an angle of 40 degrees, is pierced with two ports, through which project two 12-inch guns. The mounting of these guns is carried also upon the turntable, and revolves with the turret.

From the breech of the two guns a steel runway, or elevator track, extends down through the barbette to the floor of the handling room below, where its footing turns upon a step bearing located in the vertical axis of the barbette. This elevator revolves with the turret, and consequently ammunition can be carried up to the uns, no matter in what direction they are trained, whether ahead or on either beam. When the ammunition car in the handling room has been loaded an electric motor runs the car up to the breech of the gun, where the projectile and the charge are pushed from the car into the gun by means of an electrically-operated rammer, which will be noticed in our engraving at the rear of the turret, with one of the gun detachment operating the controller. All the movements connected with the loading and elevating of the gun, and the traversing of the turret, are performed by means of electric motors, and in our latest ships the various operations are under such perfect control that a 12inch gun may be laid with as much ease and accurac as a 6-inch rapid-firer. The circular projection seen at the forward part of the turret upon the roof is the sighting hood, from which the officer in command of the turret controls the sighting of the guns.

\section{To Get More Heat From a Fadiator.}

There are a good many roọms where the radiator is either too small or the steam pressure is too low to maintain a comfortable temperature in severe weather. If the tenant is enjoying the many advantages afthe matter can easily be remedied. Take the fan that kept you cool all summer and set it where it can blow against a large part of the radiator's surface Turn it on at low speed, or at high if necessary, and your cold room will soon be thoroughly warmed. The philosophy of the thing is that steam at a low pressure carries much less latent heat than steam at a high pressure, and therefore warms the radiator so poorly that only a slight draft of air rises around the pipes, and condensation is slow. Vvith the fan in operation there is a forced draft against the radiator that conducts a great deal more heat away from the iron, cooling it so that much more condensation of steam occurs inside it. The heat thus snatched from the reluctant radiator is held in the circulating atmosphere of the room, which is soon changed from cold to warm at a trifling cost for electric energy.-Electric City.

\section{Death of Ernest Kempton Adams.}

In the death of Ernest Kempton Adams, the profession of electrical engineering has lost one of its most promising members. Although only a very young man, Mr. Adams had been associated with the development o the stupendous Niagara enterprise. Despite his years, he left behind him no less than two hundred and fortyone inventions in diverse branches of physics. His electrical work embraced the designing of almost every type of electrical machinery, including generators, motors, transformers, measuring instruments, contact devices, and switches. Everyone of these embodied some practical improvement. Clock movements, acoustic instruments, physical apparatus, and even psychological instruments were designed by Mr. Adams, all of them affording evidence of most wonderful ingenuity. In purely physical work Mr. Adams's most noted achievement was an electrical repetition of Foucault's famous pendulum experiments. Akin to this is his atmospheric temperature clock, based on the high expansion coefficient of wood alcohol as a means of continuous operation. Mr. Adams had the reputation of being one of the finest draftsmen in his profession. Indeed, instructors in the Department of Electrical Engineering in Columbia University, the institution at which he took his degree, still point with admiration to some dynamo and motor drawings of his which are considered excellent achievements of their kind. In memory of his work, the Ernest Kempton Adams fund or physical research has been donated to Columbia University, for the purpose of promoting research in physical sciences.

\section{Cativentand}

\section{The New York Harbor Entrance.}

To the Editor of the Scientific American:

In your article of January 7, 1905, on the "New York Harbor Entrance," the following point seems to be overlooked:

At the present time there are across the wide submerged flats between Coney Island and Sandy Hoo several channels of moderate depth. The article shows Hook northward across this area, thus narrowing the entrance.

As the channels are created and maintained by the tidal flow, may we not look for a single, much deeper and better channel after the above narrowing ha taken place? In other words, is not the approaching catastrophe, pointed out by Prof. Haupt, a blessing in disguise, but not wholly unrecognizable? Cassius E. Gillette, Major of Engineers, U. S. A

San Francisco, Cal., January 21, 1905.

\section{The Black Lily.}

To the Editor of the Scientific American:

In the ScIentific AMERICAN of October 22, I find a description of a peculiar flower which you call "black lily," found in the Philippines by two teachers.

This flower "has not yet apparently been noticed by scientists," you "write. It is, however, very well known by scientists, at least by German and Dutch scientists. In this country (Isle of Sumatra) you can find many of them.

The scientific name is Amorphophallus campanu formis Blume. It is not a member of the order Lilaceii, but of the Aroidex, and no real flower, but a "spadix." The plant is in all its peculiarities very well known to the Dutch of East India, but you must not forget that we are here some centuries, and you in the Philppines only a few years.

I suppose that a botanist can explain the matter to you, if you tell him that this member of Aroidex is composed of many flowers together and seems to be only one. D. H. AREN s, JR., Medical Officer.
Tebing Tinggi Palembang, Sumatra, Dutch Eas

India, December 6, 1904

\section{What Farmers in the Wheat Belt Need.}

\section{To the Editor of the Scientific Americ: an:}

There are two things especially needed by the farThe wheat belt, of whom I am one.

The first; and by far most important, is an automatic shocker attachment to our reaping machines: the second is a practical traction engine adapted to farm and road work in a country where the soil is oose and friable.

As to the engine first: It should combine greater traction power than the average threshing engine, with minimum weight and water consumption. It should be very simple in construction, and buiit for hard, rough work. Possibly such an engine is on the market, but I have seen nearly all the standard makes and they do not fill the bill from the standpoint of the farmer seeking an efficient farm and road motor.

The automatic shocker is an urgent necessity. It is the one remaining thing needed to insure our harvests being gathered. "Hobo" labor is costly and inefficient. The waste from poor shocking alone would annually amount on the average farm to the cost of such an appliance. It must, to be efficient, do the following things: (1) Hold, place, and discharge, standng and with heads well knit together, not less than seven or eight bundles. (2) Be absolutely under control of driver as to moment of discharge. (3) Not shell over-ripe grain. (4) Add not more than twoborse draft to the machine. (5) Be simple, strong, easily adjusted, and able to handle bundles made from lodged grain. (6) Able to increase or decrease bundle in shock according to size, and general condition.

In my opinion such a shocker can be better adjusted to the header than to the binder type of reaping machines. A shock-forming table behind a header would allow of a lateral discharge of the finished shock without materially increasing the width of the machine. That type of machine, 12-foot cut, could be handled by eight horses and one man, and would have a cutting capacity of about thirty acres daily.

$$
\text { Hugir J. Hughes. }
$$

Hannaford, N. D., December 23, 1904.

The rotary cement kiln was invented by Frederick 